\title{
Effectiveness of role play in enhancing the speaking skills of the learners in a large classroom: An investigation of tertiary level students \\ PRISCILLA ISLAM \& TAZRIA ISLAM
}

\begin{abstract}
This investigation looks at enhancement in learners' speaking skills through role play in groups in a large classroom and this study also examines the teacher's assessment of students for further development of their speaking skills. About one-hundred twenty students of the department of English, Stamford University Bangladesh were involved in this investigation process from January 2012 until April 2012 in the speaking classes. For the research, qualitative data were collected in the form of questionnaires, group interviews, classroom observation, and students' performance evaluation result. The result from class room observations of students' performance has been presented in the form of graphic analysis. The result shows learners' improvement in speaking skills through role play and how the positive attitudes of teachers help to further their speaking skills. From the response of the student's questionnaire it has become obvious that role play has been enthusiastically accepted by the students as it challenges their creativity and ability to think critically, which enables them to speak more logically and confidently in the classroom. The result of the group interview shows the advantages and disadvantages of students' performance while doing the role play in groups inside the classroom and it also helps students to overcome inhibition when it comes to speaking in front of others. Through classroom observation the teacher identifies students' ability to adapt with the situational factors and also measures their fluency and use of accurate language by recording their performances. The teacher also records the gradual progress of students for further development of their speaking skills and ascertains how beneficial it is to do role play in a large classroom.
\end{abstract}




\section{Introduction}

According to Ments (1999), the word 'role' came 'from the word that was used to describe the roll of parchment on which an actor's part was written' (p. 6). He also stated, "The concept of role acts as a short hand way of identifying and labeling a set of appearances and behaviours on the assumption that these appearances and behaviours are characteristic of a particular person and predictable within a given situation" (p. 6).

A person, at first, learns to speak in native language to convey a message and then gradually uses other methods like reading and writing to communicate with others. Similarly, when a person targets to acquire a second language, the speaking method is very effective for acquisition. In Bangladesh, the other methods are given more priority for second language acquisition and for that reason students find it difficult to speak and communicate in the target language.

In private universities of Bangladesh, the medium of language that is used for class room interaction is English. However, in Bangladesh, most of the students are from Bengali medium. As a result, when students are given a task in classroom, they find it difficult to express their feelings in the target language as their native language stands as a barrier. The students usually do not get exposure to the right environment to practise speaking in English as it is not practised nationwide. As a result, in the classroom, when they are asked to give a speech they do not feel at ease. To overcome this problem, role play can be used as an effective tool to help the students regain confidence. In an English speaking class, it is important for the students to comprehend the situation to communicate effectively outside of the classroom. Role play is the medium which enables the students to get an idea about different situations through various activities taken from the scenario of real life.

According to Qing (2011), "Role play is defined as the projection in real life situations with social activities" (p. 37). Ments (1999) says, "In a role play each players act as a part of the social environment of the others and 
provides a framework in which they can test out their repertoire of behaviours or study the interacting behavior of the group" (p. 5).

When students were assigned a situation to role play in, they had put in the effort to think of the appropriate language that could be used to express their views and thoughts for communication. It also helped them to acquire speaking skill and oral fluency, which also helped to boost their confidence level. As speaking skill requires more 'practice and exposure', role play can play an effective role. A clear observation of the similarly assigned situation helped the students to adapt to the moods and vocal expression of the given situation, which they could then perform. For example, when they were assigned to play the roles of a salesman and a customer, they were introduced to a 'different social context' which was new, interesting, and challenging for them. It gave them an opportunity to show their creativity because the life style, language, emotion, environment, expression and body language would be different. As they took preparation for the play, it not only helped them to gain back their confidence but also helped in acquiring fluency in the target language. In role play, although as teachers we gave them selected topics, they selected the words and phrases of their own, which helped them to choose suitable words that suited the situation and also helped them to increase their vocabulary.

In a classroom, besides other oral activities like picture description, storytelling and quizzing, we have also given them role play. In Bangladesh, students from Bengali medium schools and colleges usually do not practise speaking using role play technique. For this reason, we assigned them with role play for practising speaking as it was new and it challenged them to be creative. Communication was not confined in one situation and role play gave them the scope to play a series of different situational interactions. Another reason was that it helped them to practise English in a controlled situation so that they could gain confidence to perform in a 'real life situation'. However, role play took up a lot of time, it became difficult for the teachers to accommodate the activity for all students within the allocated class time. In a large class, when students 
were assigned to work in groups, it became difficult for the teachers to evaluate the students individually as all of them engage in different activities at a time. Moreover, for lack of proper logistic support, the teacher could not record their performance all the time to evaluate afterwards. Although the time limitation for each play was allocated, most of the time, they exceeded the time by two, three minutes as it was left to the team members to divide the allocated time among themselves.

We noticed that the students were initially hesitant when we assigned them a role play. They were reluctant initially because they were not familiar with such activities. Through our research, we wanted to find out whether a series of role play could bring any effective changes in their attitude as well as their speaking skills.

\section{Literature Review}

Ments (1999) said, "The most obvious uses of role-play are in those areas which deal primarily with aspects of communication" (p. 19). In our speaking class the objective was to see how well the students communicate through language. Since role play is communication based technique, we applied it to see its effectiveness through various situations in controlled environment. Role-playing gives 'students the opportunity to practise interacting with others in certain roles' and regarding purpose of roleplaying he said, "their aim is to feel, react and behave as closely as possible to the way someone placed that particular situation would do" ( p. 9). Since role-play deals 'primarily with aspects of communication' Ments said, "it is therefore ideally suited to those subjects which deal with linguistic ability, namely languages, literacy and social skills training" (p. 19). Ments mentioned a lot of areas where role play could be used. For testing linguistic ability, he said it could be done "by devising scenes of everyday life, in particular those situations which make use of the vocabulary to be learnt, the students can be encouraged to use language in a free and interesting way" (p. 19). He also noticed that 'one is using language and other ways of communicating' and for that reason learning became 'an 
integral part of the task.' About role-play Ments said that "it expresses hidden feelings, student can discuss private issues and problems, enables students to empathize with others and understand their motivation" (p. 13). Ments mentioned that role play is "motivational and effective because it involves activity" (p. 13). Like Ments, while examining using role play on the students we also noticed that it was highly motivational because it was different from regular lecture based exercises which were monotonous for them. Through this activity, students were seen to gain a different experience related to their life and other social situation, which helped them to become more open from their rigid behavior. Ments pointed out some of the disadvantages of role play. According to him, assigned situations sometimes create conflicts among the group members as it might hurt the feelings of others' emotion (p. 16). He also mentioned that role play might be seen as 'too entertaining and frivolous' (p. 16). Beside advantages and disadvantages, he also mentioned some subject areas like 'history, sociology, literature, art, religion and politics', where role-play technique could be used. In our case study we used situations related to the subject areas mentioned by Ments and observed similar benefits and problems stated by Ments regarding role-play in his study.

Woodhouse (2007) suggested how role play could be used as a beneficial technique for 'personal development' through case studies in 'healthcare strategy' with a group of nursing students and how video recordings helped to observe the gradual progress of the individuals in 'a constructive way' $^{\prime}$ p. 75). In the case study Woodhouse noticed versatility in role play, which was an advantage as the situations could be 'familiar or strange', 'simple or elaborate' that could 'last for a day or for minutes.' Woodhouse also pointed out some more advantages that he adapted from the writings of different experts in the respective field. Such as, role play could be done 'with individuals or in group situations' and it helped to 'develop cultural competence, confidence and self-efficacy, and also 'to deal with difficult situations, such as suicide and breaking bad news.' He mentioned the usefulness 'for a range of topics, including interviewing, counseling skills, personal relationships, team working, leadership and cultural studies' (p. 
77). Woodhouse's case study was aimed to see the personal development in behavior of individuals by video-taping the performance but in our case study we video recorded the role-plays to see the gradual progress in the speaking skills of the learners.

Al-Senaidi (2009) investigated on 'The effectiveness of using role play to improve the oral fluency of Grade 4 learners' by using a series of role play giving situations a day before and video recorded to re-examine their performance. 'Learners' fluency improved over the course of the four role plays' and the learners also 'produced more chunks of language as they moved through the role plays' (p. 69). For our research work similar method was adopted for tertiary level students to test their competency in speaking and the result was satisfactory. Unlike Senaidi we gave feedback to students on the recorded performance each time and students worked on it to ensure improvement.

Liu and Ding (2009) used role-play technique to see how the students performed in groups when they were given a familiar situation to role play in. They also observed their language potency and how the errors can be corrected as well as how to give feedback to the learners for further improvement. Their observation was that if the teacher gave a familiar situation than the result would be positive and rather giving instant feedback they should be shown the video tapes with oral feedback for 'self or peer correction.' We followed the similar pattern for feedback and noticed that students performed well as they acted in a familiar situation and when they watched their recorded performances with oral feedback, they improved accordingly.

Qing (2011) experimented role-play in the intermediate level and noticed that role play could increase students' intercultural awareness and develop overall communicative competence (p. 36). The author stated, "Adopting another's cultural role creates freedom for experimentation while it also creates a significant learning situation for the participants and for the audience" (p. 38). The author also stated, "Content based role plays give 
students the unique opportunity to explore another culture in detail from a variety of perspectives. Speakers of English should be able to express themselves properly and understand the grammatical discourse, strategic, and sociolinguistic factors for any given situation based on a higher level of communicative competence" (p. 38). In our case study, we observed similar communicative development but as our learners were native they had little difficulty in expressing themselves properly using English language.

To encapsulate the above mentioned studies we find that role-play method has proven to be effective in improving learners' learning skills. Most of the researches show that learners' personal growth and development is possible using role-play as it is 'interactive, creative, interesting and motivating.' Based on these researches, we preceded with our case study to find whether role play is beneficial to students of tertiary level for improving their speaking skills. For keeping record of their progress in speaking and other factors related to it, we video recorded their performances in class and gave feedback to see its impact on them.

\section{Methodology}

\subsection{Objective of the study:}

We aimed to see the effectiveness of using role play in enhancing speaking skills of the students in a large class and also the advantage and disadvantage of role-play in the tertiary level.

\subsection{Research Questions:}

1. What are the advantages and disadvantages of using role-play as a medium to enhance speaking skills to interact accurately in a large class?

2. Is there any positive impact of the evaluation based on the recorded performance of role play on the students?

\subsection{Participants of role play:}

About one hundred and twenty students of Department of English of Stamford University Bangladesh took part in the investigation process. 


\subsection{Duration:}

The duration of the research was from January 2012 to April 2012.

\subsection{Data Analysis:}

For our first research question, we distributed survey questionnaire among the students. About a hundred students filled up the questionnaire form. Of them, about ninety percent students agreed that role play is different from other activities; about seventy percent students said that role play helped to increase their speaking ability and they also thought that they could show creativity more in role play rather than other activities. About fifty percent students found it to be an easy method to communicate as they had complete freedom to select the vocabulary. Only ten percent found it difficult as they had to act and speak.

We took a group interview of the students, where twenty students sat for the interview to share their views about the advantages and disadvantages of speaking in a large class. Five students stated that as they worked in a group, the students with less confidence benefitted from this as they got support from students who were more confident. As they divided the work into groups, they felt less burdened and it created a scope to show the talent of each individual. Eight students said that as they were confronted with a different situation, they experienced something new and interesting even though the characters in role play were familiar to them. While talking about the disadvantages of role play, five students felt that during role play, out of nervousness, they forgot their dialogues and it caused them embarrassment. On the other hand, thirteen students disagreed with the idea and said that even if they forgot the dialogues, they could continue the act by making up dialogues of their own. Seven students believed that, at times, it was difficult for them to fully manage the task within the allocated time.

We interviewed five teachers to ascertain whether role play could bring any effective changes in enhancing learners' speaking skills to communicate 
and interact accurately. We interviewed teachers who had been teaching English language courses at the tertiary level for the last six years at Stamford University Bangladesh. The teachers confirmed that role play enhanced learners' speaking skill as it enabled them to get fluency through acting and communicating with others. They also shared that the learners gained confidence after the first act and they tried to improve gradually in the following performances. As the situations were not discussed with the students beforehand, each time they performed, they tried to come up with new ideas. That showed their enthusiasm, interest and creativity.

In our case study we recorded and rerecorded the performance of the students and tried to find out whether there was any progress or not.

\subsection{Case study:}

A four members group was formed and they were asked to choose their topic for the act. They chose 'customer and salesman interaction in a shop' as their topic for their first act. Their performance was recorded in video form by the evaluators. After their first performance, they watched their video clip and at the same time they received feedback from the evaluators. They were told about the positive and negative aspects of their performance. Their use of language was limited and the pace of their performance was slow. So they exceeded the allotted time but they could still communicate and interact with one another. They understood their strengths and weaknesses and they talked about it among themselves. They took on board the suggestions from instructor for further improvement. Then the students were asked to prepare another topic for the second act. For that, they chose interaction between 'a doctor, a patient and a nurse in a hospital situation.' Their performance in the second act was again filmed and played back. In that act, the evaluators could see a significant improvement in the performance of the learners. The evaluators appreciated the students for taking their feedback positively for further improvement. The learners used moderated language and their fluency increased. So, this time round, the allotted time was fairly managed. 
Similarly, they were tested again for the third time using the same method and their improvement was observed again. For the fourth role play, the learners were tested with little preparation to see whether they could interact and communicate in an unrehearsed situation. That time the students selected a film making situation. When the act was reviewed and analyzed, the evaluators could see the gradual improvement of the learners. The students became more spontaneous and more confident to speak incorporating effective interaction and communication. They also improved in verbal fluency, using appropriate vocabulary, adapting different moods, body language and vocal expression to use in the situation.

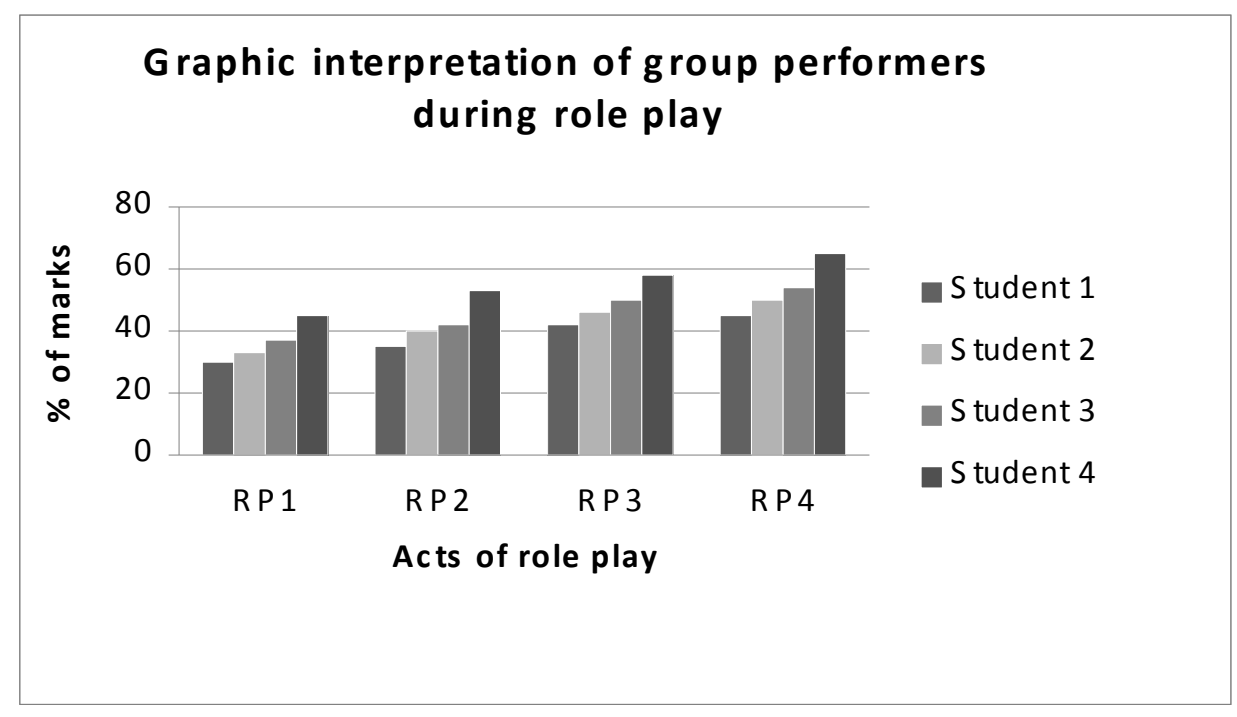

$\mathrm{RP}=$ Role Play

Figure: 3.6.1 Graphic interpretation of the group performers during role play

In this graph, we have presented the gradual progress of individual performers in a four members group. They were assessed on language, fluency, expression and spontaneity while performing in a group act. The 
group performed four different role plays where the first three columns of bars show the result of their performance with a lot of preparation and the last columns of bars show their performance with very little preparation. In the first role play, we can see the percentage of scores of the four members. The 1st performer scored $30 \%$. The 2 nd, 3rd and $4^{\text {th }}$ performers scored $33 \%$, $37 \%$ and $45 \%$ respectively. The second and third columns of bars show the gradual progress of each learner. In the last columns of bars (RP-4) we see that the 1st performer's score improved by 15\% in comparison with the first act. Similarly the $2 \mathrm{nd}$, 3rd and 4th members improved by $17 \%, 17 \%$ and $20 \%$ respectively.

\section{Limitations}

As the research was conducted on a small scale where one hundred and twenty students and five teachers took part in the investigation process, we cannot generalize the concept that role play is the effective technique for improving learners' speaking skill in other universities as the results may vary. As the research was done within four months' time, we could not apply many techniques on the learners because the learners had to sit for the research besides their regular classes. This small scale research can be taken as a sample guideline and can be used to carry out the research on a large scale.

\section{Research findings}

In our research, we have found that students were enthusiastic about role play as it was different from other activities done in class. After a series of role play, they showed remarkable improvement in their speaking ability and they were also found to be quite fluent. They became confident enough to speak in the created situation of real life scenario. They shared their 'hidden feelings' and expressed themselves without restraint. In a large class room, role play was a good technique to use to observe the performance of a number of students in a limited time constraint. They were given feedback for further improvement. We have also observed that 
the feedback that was given on the basis of the filmed video clips helped the learners to understand their weakness and strengths.

\section{Conclusion and Suggestion}

In a few words, we can say that role play technique has positive impact in improving learners' speaking skills as it gives the students a chance to explore different situations of real life and enables them to speak accurately and confidently in that situation in the target language. Although during role play in a large class room, the situation gets chaotic and the performers sometimes forget their dialogues, which create embarrassment, eventually with the help of little feedback from the teachers, this problem can be resolved. Teachers may give prompt verbal feedback or written feedback in case of technical difficulties while recording acts. 


\section{References}

Al-Senaidi, S. A. (2009). Using role play to promote oral fluency, 66-72. In Borg. S. (Ed.), Understanding English Language Teaching and Learning in Oman. Retrieved July 11, 2012, from ttp//www.moe.gov.om/Portal/sitebuilder/Sites/EPS/Arabic/IPS/Importa /tesol/3/Using \%20role\%20play\%20to\%20promote\%20oral\%20fluency.pdf

Liu, F. \& Ding, Y. (2009). Role-play in English language teaching. Asian Social Science, 5(10), 140-143. Retrieved July 11, 2012, from http://www.ccsenet.org/journal/index.php/ass/article/download/3988/35 34.

Ments, V. M. (1999). The effective use of role-play: practical techniques for improving learning ( $2^{\text {nd }} \quad$ ed.). Retrieved May 12, 2012 , from http://books.google.com.bd/books/about/The_Effective_Use_of_Role_Play. html?id=GbXOYf8aTIC\&redir_esc=y

Qing, X. (2011). Role-play an effective approach to developing overall communicative competence. Cross-Cultural Communication, 7(4), 36-39. DOI:10.3968/j.ccc.1923670020110704.317

Woodhouse, J. (2007). Role play: a stage of learning. In Woodhouse. J. (Ed.). Strategies for Healthcare Education. Radcliff Publishing LTD. United Kingdom. Retrieved March 11, 2012 from http://www.radcliffeoxford.com/books/samplechapter/0061/Woodhouse_chp8-6932e500rdz.pdf 


\section{Appendix}

\section{Questionnaire}

Fill up this section

Name:

Age:

Please respond to the statements by ticking the appropriate boxes $(\mathrm{SA}=$ strongly agree, $\mathrm{A}=$ agree, $\mathrm{N}=$ neutral, $\mathrm{DA}=$ disagree, and $\mathrm{SD}=$ strongly disagree).

\begin{tabular}{|l|l|l|l|l|l|}
\hline Question & SA & A & N & DA & SD \\
\hline 1. Role play is interesting. & & & & & \\
\hline 2. Role play is difficult. & & & & & \\
\hline 3. Role play is different from other activities. & & & & & \\
\hline 4. Role play helps to enhance speaking ability. & & & & & \\
\hline 5. It is an easy method to communicate with others. & & & & & \\
\hline 6. It helps to overcome nervousness. & & & & & \\
\hline 7. It is difficult to select a topic for role play. & & & & & \\
\hline $\begin{array}{l}\text { 8. It helps to increase fluency as it is rehearsed with } \\
\text { expressions. }\end{array}$ & & & & & \\
\hline 9. It gives an opportunity to express emotions freely. & & & & & \\
\hline $\begin{array}{l}\text { 10. The feedback after role play helps to improve } \\
\text { further. }\end{array}$ & & & & & \\
\hline 11. It helps to increase vocabulary. & & & & & \\
\hline 12. It gives a scope to show innovation. & & & & & \\
\hline $\begin{array}{l}\text { 13. In a limited time, it is difficult to fully express the } \\
\text { role. }\end{array}$ & & & & & \\
\hline $\begin{array}{l}\text { 14. Role play in groups is helpful as ideas can be } \\
\text { shared. }\end{array}$ & & & & & \\
\hline
\end{tabular}

\section{Interview questions for teachers}

Name:

Length of teaching experience:

Field:

1. Did role play enhance learners' speaking skills?

2. Did a series of role play bring any effective change in enhancing learner's speaking skills to communicate and interact accurately?

3. How did it help the learners to gain confidence? 
4. Did you discuss the situations with the learners before assigning it to them?

5. What result did you get from their act?

\title{
Interview questions for group students
}

Names of participants:

Age group:

1. Did role play help you to regain confidence? How?

2. What benefit did you get while working in groups? What sort of problems did you face in working in a group?

3. How did you feel when you got the topic for your act?

4. Could you manage the time that was given to you for the act?

\section{Unscripted Role Play}

\author{
"Film Making"
}

Four characters: Director, mother, daughter, and aunt.

\section{Act-1}

Director: I have a dream to make a film and be a millionaire. Can you fulfill my dream? Here's the plan. (Shows the script to three girls and tells them about their roles)

Three girls (together): Oh, yes, it is very easy.

Director: Really? Then why don't you give an audition.

(Pause)

Light, Camera, Action.

(One girl plays the role of an aunt; one plays the daughter and the other the mother)

\section{Act-2}

Daughter (towards her mother): Mother, I have failed in the exam.

Mother (newspaper in her hand): What! You failed in the exam? Get out of my house.

Aunt (towards the mother): You are her mother and you are rejecting her? You should give her a chance.

Director (annoyed): Cut. Cut. Cut. Is this an act? There is no expression. You should be crying (addressing the mother) coz she failed in the exam.

Mother, Daughter and aunt (together): Oh, cry. It is very easy. Very easy. 
Director: Light, camera, action.

\section{Act-3}

(Daughter, mother and aunt starts crying together)

Daughter (crying, coming towards the mother): Mother, I have failed in the exam. Mother (newspaper in her hand, crying): What, you failed in the exam? Get out of my house.

Aunt (addressing the mother, crying): You are her mother and you are rejecting her? You should give her a chance.

Director: Cut, cut, cut. What is this? Why are you crying (to three of them). She failed in the exam (addressing the mother) You should show anger. Now let's do it again.

Light, camera, action.

Act-4

Daughter (toward mother, showing anger): Mother, I failed in the exam.

Mother (newspaper in her hand): What, you failed in the exam? Get out of my house. Get out.

Aunt (toward the mother): You are her mother and you are rejecting her. You should give her a chance.

Director: Oh what is this? Why are all of you showing anger? You should know about expression, eye contact and gesture. Did you not do public speaking course? Did you not learn about expression? You (to the mother), you are the mother, you should be angry because it's your daughter who failed, and you should be sad (to the daughter) and you are the aunt so you should console the mother (to the aunt). Now let's do it again.

They all do it according to the director's instruction. 